\title{
Análise de dissertações e teses brasileiras de Educação Ambiental: compreensões elaboradas sobre o tema "mudanças climáticas"*
}

\author{
Analysis of Brazilian dissertations and thesis \\ on environmental education: understandings of climate change
}

\author{
Danielle Aparecida dos Reis ${ }^{1}$. Luciano Fernandes Silva ${ }^{2}$
}

\begin{abstract}
Resumo: Este trabalho apresenta os resultados de um estudo cujo objetivo foi analisar as compreensões elaboradas pelo campo de pesquisa em Educação Ambiental (EA) sobre controvérsias e complexidades inerentes ao tema mudanças climáticas. Os dados foram construídos a partir da análise de dissertações de EA que abordam o tema mudanças climáticas de maneira central em seus propósitos investigativos. Para a delimitação do corpus documental, realizou-se um levantamento bibliográfico das teses e dissertações de EA - constantes no Banco de Teses da CAPES - que foram defendidas entre 1987 e 2010, sendo selecionadas 11 dissertações. Os trabalhos foram analisados tomando como referência os procedimentos da "Análise de Conteúdo". Os resultados indicam que o campo da EA apresenta informações importantes sobre as mudanças climáticas, entretanto, pouco revela sobre as suas complexidades e controvérsias. Conclui-se que, embora sejam enfocadas por poucos trabalhos, as controvérsias científicas associadas ao fenômeno são as mais recorrentes.
\end{abstract}

Palavras-chave: Mudança climática. Educação Ambiental. Levantamento bibliográfico. Tese. Dissertação.

\begin{abstract}
This work presents the results of a research project that aimed at analyzing the understandings of controversies and complexities inherent to the topic of climate change elaborated within the field of environmental education (EE). The corpus has been constructed by means of the analysis of dissertations and theses in the EE area that had climate change as a central aspect of their research objectives. The documental corpus is dissertations and thesis in the field of EE education concluded between 1987 and 2010 selected from the CAPES Thesis and Dissertation Database. Eleven dissertations have been selected and then analyzed using "Content Analysis" procedures. The results suggest that the EE field provides significant information on climate change but reveals little of its complexities and controversies. It can be thus be argued that controversies are focused on in few works, and scientific controversies related to the phenomenon are the most frequent ones.
\end{abstract}

Keywords: Climate change. Environmental education. Bibliographic research. These. Dissertation.

\footnotetext{
* Este artigo apresenta parte dos resultados obtidos na dissertação de mestrado da primeira autora.

${ }^{1}$ Universidade Estadual Paulista (Unesp), Rio Claro, SP, Brasil. E-mail: < dani_aparecidareis@yahoo.com.br>

${ }^{2}$ Universidade Federal de Itajubá (UNIFEI), Departamento de Física e Química, Itajubá, MG, Brasil.
} 


\section{Controvérsias associadas à crise ambiental}

As discussões centradas na chamada "crise ambiental" compõem diversos debates científicos, políticos, econômicos e sociais voltados para a questão ambiental. A análise dessas discussões indica que os discursos sobre este tema são acompanhados por controvérsias de diferentes naturezas.

Para Silva e Carvalho (2007, p. 1), por exemplo, as controvérsias são características fundamentais, inerentes aos diferentes discursos voltados para a problemática ambiental, e "[...] embora a ideia de "crise" e de "problema" ambiental seja parte constituinte do núcleo do discurso construído por vários desses grupos [ambientalistas], esse discurso é marcado por dissensos, controvérsias, posicionamentos e perspectivas diferentes".

De acordo com as definições de Rudduck (1986), um tema controverso é caracterizado como uma questão responsável por gerar diferentes posicionamentos entre as pessoas e por envolver diferentes juízos de valor. Reis (2009) define que as controvérsias podem ser classificadas como: científicas (aquelas que estão diretamente relacionadas às questões internas e restritas ao âmbito da comunidade científica), sociocientíficas (aquelas diretamente relacionadas aos impactos sociais produzidos pelas inovações científicas e tecnológicas) e socioambientais (aquelas que emergem dentre o meio político, social e/ou científico, e que resultam das diferentes percepções relativas ao impacto ambiental sobre a sociedade). As autoras Ribeiro e Kawamura (2014, p. 167) consideram que:

[...] as controvérsias não são coisas a serem superadas, mas têm um caráter intrínseco, na medida em que são o caminho para explicitar contradições. As contradições, por sua vez, são os elementos que movem as dinâmicas sociais, como expressão de diferentes relações econômicas, objetivos e valores.

É interessante destacar que muitas das controvérsias relacionadas à temática ambiental advêm de uma realidade que pode ser caracterizada e compreendida por meio da sua dimensão complexa. Por isso, a complexidade apresenta-se como uma forma de olhar para o mundo e, a partir dela, pode-se entender alguns dissensos relacionados à temática ambiental. Para Morin (2007, p. 68), uma realidade complexa diz respeito "[...] à incapacidade de ter certeza de tudo, de formular uma lei, de conceber uma ordem absoluta". Por isso, reconhecer uma realidade complexa significa "[...] compreender que jamais poderemos escapar da incerteza e que jamais poderemos ter um saber total apresentando assim maneiras diversificadas de se compreender a realidade" (MORIN, 2007, p. 69).

Para o autor supracitado, a partir da consideração de que a realidade é complexa, é praticamente impossível evitar as contradições. Segundo Prigogine (1996), o reconhecimento da complexidade da natureza possibilitou que fossem repensadas as certezas que historicamente foram a ela atreladas com a formulação de leis universais.

Frente essas considerações, entende-se que a análise das questões ambientais segundo o viés da complexidade permite compreender e reconhecer a existência de controvérsias relacionadas com a temática ambiental. Nesse sentido, a Educação Ambiental (EA) é apresentada 
Análise de dissertações e teses brasileiras de Educação Ambiental: ...

como um dos meios que podem explicitar de maneira clara as controvérsias associadas à questão ambiental por meio da complexidade.

\section{Educação Ambiental e temas complexos e controversos}

A necessidade de modificar a relação estabelecida entre o ser humano e a natureza e a constante busca de modelos de ação que indiquem algumas medidas que possam minimizar, corrigir ou, até mesmo, reverter os impactos ambientais têm suscitado importantes reflexões e apontado diferentes caminhos a serem seguidos para que se efetivem tais mudanças. Nesta perspectiva, o processo educativo é visto como um agente eficaz de transformação, que pode contribuir efetivamente para o despertar de um conhecimento mais abrangente sobre a temática ambiental (CARVALHO, 2006). De maneira específica, a Educação Ambiental (EA) é apresentada como um interessante meio para a superação da "crise ambiental".

Ao mesmo tempo, cabe destacar que a formação dos conceitos sobre a temática ambiental nas práticas de EA deve levar em conta o acesso à dimensão controversa deste tema. Nicolai-Hernandez e Carvalho (2006, p. 130) indicam que, a partir da abordagem das controvérsias associadas aos temas ambientais, os conceitos como "harmonia nas relações sociedadenatureza", "equilíbrio da natureza" e "visão holística" podem ser reformulados.

Nesse sentido, entende-se que a discussão sobre as controvérsias associadas à temática ambiental em sala de aula apresenta possibilidades interessantes para a elaboração de propostas inovadoras de EA. Ribeiro e Kawamura (2014) reconhecem a necessidade de se introduzirem as discussões referentes aos aspectos controversos das questões ambientais em sala de aula, sobretudo, por possibilitarem o desenvolvimento de posicionamentos críticos em relação aos temas controversos discutidos. Para as autoras:

Questões controversas reais são, de fato, problemas em aberto, em um cenário que favorece a identificação de contradições, de interesses e confrontos sociais. Um cenário que representa de forma mais próxima o contexto ambiental vivenciado, complexo e contraditório, onde nos é dado atuar. Nesse espaço, julgamentos ou pontos de vista podem ser constantemente revistos, reavaliados, recolocados, num ambiente de aprendizagem permanente com a evolução dos acontecimentos reais. (RIBEIRO; KAWAMURA, 2014, p. 167)

Cabe ainda destacar que a abordagem dessas controvérsias nas propostas educativas possibilita a promoção de ambientes educativos em que os educandos são incentivados a criticar e a questionar os problemas socioambientais. Nesse exercício, “[...] estaremos, educandos e educadores, nos formando e contribuindo, pelo exercício de uma cidadania ativa, na transformação da grave crise socioambiental que vivenciamos todos" (GUIMARÃES, 2007, p. 31).

A partir destas considerações sobre a temática ambiental e o processo educativo, entende-se como pertinente a elaboração de investigações que possibilitem analisar se o campo de pesquisa em EA tem se voltado para trabalhos que valorizem a abordagem dos temas controversos, segundo a perspectiva da complexidade. 


\section{Educação Ambiental e mudanças climáticas: o problema de pesquisa}

As considerações anteriormente apresentadas evidenciam a relevância da elaboração de investigações que indiquem quanto a complexidade e as controvérsias relacionadas aos temas ambientais estão sendo destacadas no campo de pesquisa da EA.

Um tema ambiental que, de modo especial, destaca-se pelas controvérsias a ele relacionadas é o das mudanças climáticas. A literatura especializada sobre o referido tema é composta por controvérsias que envolvem aspectos políticos, econômicos, científicos e sociais (LIMA, 2009). Andrade (2007), por exemplo, indica que as questões em torno desse fenômeno são caracterizadas por envolver inúmeros debates controvertidos sobre as origens, as causas, os efeitos e as formas de amenizar as consequências ambientais e sociais das alterações climáticas.

Considerando o potencial educativo da abordagem das controvérsias associadas a este tema, nesta investigação procurou-se identificar e analisar as compreensões que são elaboradas pelos pesquisadores do campo da EA sobre o fenômeno das mudanças climáticas. Para uma investigação deste caráter, entendeu-se que uma pesquisa de natureza documental seria a mais indicada. Nesse sentido, a produção teórica da área se revelou como uma das mais promissoras a serem investigadas, já que a pesquisa em tais documentos possibilitaria a sistematização e a valorização do conhecimento já produzido no Brasil, pelo campo da EA, sobre o tema mudanças climáticas.

Levando em consideração tais constatações, neste trabalho, optou-se pela realização de uma pesquisa a partir da produção teórica da EA, representada pelas dissertações e teses deste campo de pesquisa que tratam do tema mudanças climáticas de maneira central, em seus propósitos investigativos. Entende-se que essa é uma oportunidade de reunir o que se tem pesquisado na EA sobre temas que são ricos em controvérsias e apresentam possibilidades de apontamentos das complexidades inerentes aos fenômenos socioambientais.

Tendo como base as dissertações e teses de Educação Ambiental que versam sobre o tema mudanças climáticas, este trabalho buscou responder à seguinte questão: que aspectos do tema mudanças climáticas são destacados nas teses e dissertações de Educação Ambiental (EA) em que esta temática é central? O que a análise das informações apresentadas nesses trabalhos revela sobre as compreensões elaboradas no campo de pesquisa da EA sobre o referido tema?

A partir deste problema, destacam-se os seguintes objetivos:

- Identificar as controvérsias associadas ao tema que são apresentadas nesses trabalhos e analisar se estas são de natureza científica, política, econômica e/ou social;

- Identificar se a produção teórica analisada apresenta propostas de Educação Ambiental que abrangem o tema mudanças climáticas e analisar quais controvérsias relativas ao fenômeno são destacadas nestas atividades.

\section{Procedimentos de pesquisa}

Nesta pesquisa foi feita uma revisão documental que se fundamenta em abordagens de natureza qualitativa/interpretativa. Este trabalho articulou-se diretamente com o Projeto 
Análise de dissertações e teses brasileiras de Educação Ambiental: ...

de Pesquisa "A Educação Ambiental no Brasil: análise da produção acadêmica (dissertações e teses)" (CARVALHO et al., 2009). Esse Projeto de Pesquisa, também conhecido pelo termo "EArte", possui o objetivo de mapear a produção das teses e dissertações brasileiras de EA, propondo a realização de uma pesquisa do tipo estado da arte ou estado do conhecimento.

\section{Procedimentos de coleta do material: a definição do corpus documental}

No presente estudo, realizou-se um levantamento bibliográfico de dissertações e teses de EA presentes no Banco de teses da Coordenação de Aperfeiçoamento de Pessoal de Nível Superior (CAPES, 2105). Foram coletadas as dissertações e teses defendidas entre 1987 e 2010 , já que 1987 foi o ano de criação do referido Banco e 2010 foi o ano anterior ao do ingresso da primeira autora deste trabalho no curso de pós-graduação em Educação.

No site da Capes realizou-se a busca dos trabalhos utilizando-se três palavras-chave associadas ao termo "Educação Ambiental”: "mudanças climáticas", "aquecimento global” e, por último, "efeito estufa", selecionando-se a opção de busca por "todas as palavras". Com estes critérios, foram identificadas 45 dissertações de mestrado e duas teses de doutorado.

Posteriormente, realizou-se a leitura atenta dos resumos desses 47 trabalhos. Nesta leitura, buscou-se identificar os trabalhos que fizessem referências ao tema mudanças climáticas (aparecendo de maneira explícita no título, resumo ou palavras-chave) e que, ao mesmo tempo, fossem de EA. Para definir se o trabalho era de EA, apenas com base nas informações presentes no banco de teses da CAPES, foram utilizados os critérios determinados no âmbito do projeto EArte (2015).

A partir da leitura dos 47 resumos, foram selecionadas 22 dissertações para compor o corpus preliminar deste trabalho, sendo que nove foram classificadas como "dúvida". Feito esse primeiro mapeamento, iniciou-se a fase de busca das dissertações na íntegra, a fim de se delimitar o corpus documental que seria submetido à análise dos textos completos.

Dos 22 trabalhos, foi possível ter acesso ao texto completo de 21 dissertações. Dentre esses, alguns se enquadravam na categoria de "dúvidas" e, após a análise dos textos na íntegra, 5 foram excluídos do corpus (já que não eram de EA). A única dissertação a que não se teve acesso ao texto completo foi incluída no corpus, visto que, de acordo com as informações fornecidas pela CAPES, é de EA e trata das mudanças climáticas.

Sendo assim, por meio dos critérios definidos, foram localizadas no banco de teses da CAPES, até o ano de 2010, 17 dissertações de EA que abordam o tema mudanças climáticas de maneira central em seus propósitos investigativos.

Entretanto, para a análise dos textos completos, foram selecionadas 11 dissertações, compreendidas entre os anos de 2003 a 2010. Esta delimitação foi feita já que, em cinco dissertações, embora o tema mudanças climáticas estivesse diretamente relacionado ao propósito de investigação, não foram apresentadas maiores reflexões sobre o tema, como identificado nos demais trabalhos.

O Quadro 1 apresenta o ano de defesa, autor, título e código de identificação das dissertações que foram submetidas à análise dos textos completos. 
Quadro 1. Informações referentes às dissertações que foram submetidas à análise do texto completo

\begin{tabular}{|c|c|c|c|}
\hline ANO & Autor & Título & Código \\
\hline 2003 & $\begin{array}{l}\text { Lilian Cristiane Almeida } \\
\text { dos Santos }\end{array}$ & $\begin{array}{l}\text { A física na Educação Ambiental: a questão do efeito } \\
\text { estufa }\end{array}$ & D1 \\
\hline 2003 & Mário Luiz de Farias & $\begin{array}{l}\text { Combustão e seus efeitos: um estudo sobre } \\
\text { concepções de alunos do ensino técnico do CEFET- } \\
\text { RS, visando à Educação Ambiental }\end{array}$ & D2 \\
\hline 2007 & Ana Paula Lückman & $\begin{array}{l}\text { Educação, jornalismo e meio ambiente: leituras sobre } \\
\text { a crise ecológica no contexto do aquecimento global }\end{array}$ & D4 \\
\hline 2008 & Jaison Luis Cervi & $\begin{array}{l}\text { A pegada ecológica do município cidade do Rio de } \\
\text { Janeiro }\end{array}$ & D5 \\
\hline 2008 & Lauro Daros & A práxis docente e a pedagogia planetária emergente & D6 \\
\hline 2008 & Walter Luiz da Silva Junior & $\begin{array}{l}\text { A Educação Ambiental através do estudo da energia } \\
\text { renovável e não renovável }\end{array}$ & D8 \\
\hline 2008 & Lilian Siqueira & $\begin{array}{l}\text { O enfoque interdisciplinar dos problemas ambientais } \\
\text { contemporâneos e o ensino de química: um quadro a } \\
\text { partir de livros didáticos do Ensino Médio }\end{array}$ & D9 \\
\hline 2008 & Dinair Veleda Teixeira & $\begin{array}{l}\text { A ética no discurso do jornal Zero Hora sobre as } \\
\text { mudanças climáticas }\end{array}$ & D10 \\
\hline 2009 & Arnaldo Telles Ferreira & $\begin{array}{l}\text { A inconveniência de uma verdade: representações } \\
\text { sociais de estudantes universitários sobre o } \\
\text { aquecimento global }\end{array}$ & D11 \\
\hline 2010 & $\begin{array}{l}\text { Luis Gustavo D'Carlos } \\
\text { Barbosa }\end{array}$ & $\begin{array}{l}\text { O debate sobre o aquecimento global em sala de aula: } \\
\text { o sujeito dialógico e a responsabilidade do ato frente a } \\
\text { um problema sociocientífico controverso }\end{array}$ & D13 \\
\hline 2010 & Grazielle Zeni & $\begin{array}{l}\text { A dimensão ambiental no contexto ensino } \\
\text { aprendizagem: avaliação do jogo didático nas aulas de } \\
\text { biologia }\end{array}$ & D16 \\
\hline
\end{tabular}

Fonte: elaborado pelos autores. 
Análise de dissertações e teses brasileiras de Educação Ambiental: ...

\section{Procedimentos de análise de dados}

Para sistematizar e analisar as informações coletadas, foram elaboradas, por meio da leitura dos textos completos, fichas de leitura para identificar a dissertação e registrar as passagens ou excertos dos textos que apontassem os elementos (palavras, frases, expressões, parágrafos) que eram importantes para a pesquisa. Foram escolhidos aqueles excertos que respondiam, de alguma maneira, as indagações feitas por esta investigação, sendo que os critérios para a escolha dos excertos estavam diretamente relacionados com os objetivos específicos deste trabalho.

Após a sistematização das informações coletadas, procedeu-se à análise dos dados. Para isto, utilizou-se o procedimento conhecido pelo termo "Análise de Conteúdo" (BARDIN, 2009). Dentre as diferentes técnicas de Análise de Conteúdo, este trabalho se apoia naquela reconhecida por análise temática ou categorial. No caso deste trabalho, optou-se pela construção das categorias a posteriori, elaboradas a partir da leitura das dissertações que constituem o corpus documental.

As categorias de análise foram elaboradas por meio dos seguintes passos:

1. Leitura dos textos completos das $\mathbf{1 1}$ dissertações: Nesta primeira leitura, todos os excertos que tratavam sobre os diferentes aspectos das mudanças climáticas foram separados em um documento. Foram elaborados 11 documentos diferentes, um para cada dissertação;

2. Leitura dos excertos selecionados: Nesta etapa, foi feita a releitura dos excertos selecionados. Neste momento, os excertos semelhantes, ou seja, que faziam referência ao mesmo aspecto do tema mudanças climáticas, foram agrupados em um novo documento;

3. Leitura dos agrupamentos elaborados: Os excertos selecionados e agrupados a partir da etapa anterior foram relidos. Durante essa releitura, buscou-se identificar uma palavra ou frase que pudesse representar a ideia presente em cada agrupamento de excertos;

4. Releitura dos agrupamentos: Realizou-se a leitura dos agrupamentos anteriores e os excertos constituintes de cada categoria foram reorganizados, o que permitiu um novo reagrupamento dentro das categorias elaboradas, resultando nas subcategorias;

5. Análise dos dados: A partir desses dados e com base no referencial teórico, partiu-se para a análise de tais dados com o intento de verificar como o campo de pesquisa da EA, aqui retratado por suas teses e dissertações, compreende o tema mudanças climáticas.

No próximo item, apresentam-se detalhes da análise dos excertos agrupados em cada categoria e subcategoria.

\section{Compreensões elaboradas no campo da Educação Ambiental sobre o tema "mudanças climáticas"}

A análise dos textos das dissertações selecionadas, a partir do foco da relação entre a Educação Ambiental e as mudanças climáticas, permitiu a sistematização de categorias e subcategorias para discussão dos dados referentes a essa questão, conforme exposto no Quadro 2.

Tendo elaborado as categorias, posteriormente, realizou-se a análise dos excertos segundo o referencial teórico desta pesquisa. Na sequência, são apresentados os dados que indicam a compreensão do campo da EA sobre o tema mudanças climáticas. 
Quadro 2. Categorias e subcategorias elaboradas a partir de dados obtidos com as dissertações e as teses de Educação Ambiental que tratam do tema mudanças climáticas

\begin{tabular}{|c|c|}
\hline Categorias & Subcategorias \\
\hline \multirow[t]{2}{*}{ Causas } & Interferência humana sobre a natureza \\
\hline & Causas tanto naturais quanto antrópicas \\
\hline \multirow{2}{*}{ Consequências } & Catástrofes climáticas \\
\hline & Impactos na sociedade/economia/saúde \\
\hline \multirow[t]{4}{*}{ Medidas de mitigação } & Redução da utilização de combustíveis fósseis \\
\hline & Energia Alternativa \\
\hline & Sequestro de Carbono \\
\hline & Soluções tecnológicas \\
\hline \multirow{2}{*}{$\begin{array}{l}\text { Articulações propostas entre } \\
\text { práticas de Educação Ambiental } \\
\text { e o tema mudanças climáticas }\end{array}$} & Propostas educativas \\
\hline & $\begin{array}{l}\text { Contribuições do trabalho com o tema mudanças climáticas } \\
\text { para a EA }\end{array}$ \\
\hline
\end{tabular}

Fonte: elaborado pelos autores.

\section{Principais controvérsias e complexidades destacadas por meio das informações sobre o fenômeno}

Com relação às causas associadas às mudanças climáticas, alguns posicionamentos presentes nas dissertações indicam menções às complexidades inerentes ao fenômeno. De acordo com o autor da dissertação D11, as causas deste fenômeno: “[...] não podem ser problematizadas apenas pelo constante aumento dos gases de efeito estufa, mas compreendido dentro de uma complexa trama de processos históricos, sociais, biológicos, das múltiplas inter-relações de todos os fenômenos com a realidade global e local". (D11, p. 23)

Esta consideração aponta para a complexidade dos fenômenos climáticos, sobretudo ao indicar que o sistema terrestre é dinâmico e aberto, sendo sujeito à interferência de diversas variáveis, como os fenômenos naturais e a intervenção antrópica (WATANABE-CARAMELLO, 2012). Conforme bem destacado pela autora da dissertação D1, o “[...] nosso planeta é um sistema complexo e dinâmico. Os domínios orgânicos, gasosos, líquidos e sólidos da Terra são intimamente interligados. Uma mudança em uma das partes do sistema provavelmente afetará outras partes" (D1, p. 36).

Todavia, em outras dissertações - como em D4, D5, D6, D8, D11 e D16 - foi possível identificar considerações dos autores, os quais apontam que a intervenção antrópica sobre o meio ambiente é a principal (senão única) causa das mudanças climáticas. O autor da dissertação D5, por exemplo, indica que: "Grande parte do aquecimento observado nos últimos 50 anos é causado por atividades humanas (uma certeza maior do que 90\%) e conclui-se [...] que o aquecimento do sistema climático é claro e patente (D5, p. 92-93)”. 
Em todos os trabalhos, nos quais este posicionamento está presente, é frequente a indicação de que, após a Revolução Industrial, houve um expressivo aumento de deposição de dióxido de carbono na atmosfera, e que este tem um peso significativo na ocorrência das mudanças climáticas. Na dissertação D6, o autor aponta que: “[...] a Revolução Industrial e o uso crescente de combustíveis fósseis e a acumulação de gases de efeito estufa na atmosfera começou a produzir um aquecimento global” (D6, p. 95).

Informações desta natureza possibilitam um repensar da relação historicamente estabelecida entre a sociedade e a natureza. Watanabe-Caramello (2012, p. 202) chama a atenção para o fato de que se deve "[...] tomar o ser humano enquanto parte do sistema e não como mero espectador dos fatos", ou seja, a ação humana sobre a natureza não deve ser desprezada. Por outro lado, a autora destaca que, ao mesmo tempo, deve-se "[...] buscar um olhar mais atento para as relações complexas e as incertezas que se estabelecem no meio ambiente". Nesta perspectiva, é destacado, na dissertação D1, que:

Estamos, com certeza, lançando na atmosfera gases-estufa e outros, resultantes de alguma atividade antropogênica. Que eles podem contribuir para o aumento da temperatura terrestre, devido à absorção dos gases estufa, é uma hipótese viável. Porém, se isso está efetivamente contribuindo, e de quanto é essa contribuição, ainda são questões em aberto. (D1, p. 53, grifos da autora)

Ou seja, conforme destacado no excerto anterior, embora existam dados que indiquem, de forma inequívoca, que a temperatura superficial terrestre esteja se elevando concomitantemente com as concentrações de $\mathrm{CO}_{2}$ na atmosfera, também, é pertinente considerar incertezas e controvérsias associadas ao peso que esta ação humana possui sobre as alterações climáticas. $\mathrm{Ou}$ seja, ao discorrer sobre este assunto, deve-se deixar clara a ideia de que se tratam de hipóteses e que estas estão sujeitas a variações.

Embora essa informação possa ser válida, é importante considerar outras discussões que envolvem o assunto. A autora da dissertação D1 apresenta que, embora pareça haver uma relação entre o aumento da concentração de $\mathrm{CO}_{2}$ e o aumento de temperatura, não é possível afirmar com certeza absoluta qual é a contribuição efetiva deste gás para as variações climáticas, já que "[...] os dois [concentração de $\mathrm{CO}_{2}$ e temperatura] não crescem na mesma proporção, o que nos leva a pensar que não é uma relação direta, ou seja, se dobrar a concentração de $\mathrm{CO}_{2}$ na atmosfera não necessariamente dobrará a temperatura média terrestre” (D1, p. 51).

Ainda, em relação às possíveis causas que o campo de pesquisa da EA elenca para o fenômeno das mudanças climáticas, reuniram-se os excertos que reconhecem a origem natural deste fenômeno, sendo estes identificados nas dissertações D1, D2, D9, D10 e D13.

Nessas dissertações, os autores indicam o caráter natural do fenômeno. Além disso, apontam que existe a possibilidade de o ser humano estar de alguma forma contribuindo para intensificar as mudanças no clima, entretanto, esta não deve ser considerada como única causa. Como destacado na dissertação D9, existem controvérsias científicas relativas às causas das mudanças climáticas:

Embora haja frentes de pesquisas que sugerem que as atividades humanas não têm tanto poder em provocar, por exemplo, um aumento na concentração de gás carbônico (o que seria um dos motivos para se ter um aumento 
no efeito estufa e no aquecimento global do planeta), mas sim que as causas para esses fatos vão muito além do que essas atividades humanas poderiam realizar (fenômenos naturais), há um grande número de pesquisas que acordam que muitas dessas atividades, aumentadas em grandes proporções desde o início da Revolução Industrial, realmente têm participação no aumento desses fenômenos citados. (D9, p. 113)

Conforme destacado na dissertação D1, um dos primeiros argumentos apresentados em favor das causas naturais do fenômeno está no estudo da história geológica do planeta, que fornece indícios de que:

[...] a temperatura terrestre não é constante no decorrer do tempo, e já esteve abaixo dos valores atuais, mas também esteve acima. Percebemos a existência de períodos mais ou menos quentes. E também que estamos num período de maior temperatura, mas não podemos afirmar qual a causa desse valor para a temperatura. (D1, p. 51)

O autor da dissertação D13 apresenta que, para identificar as causas das mudanças climáticas, deve-se estudar o balanço energético Sol-Terra. De fato, o estudo deste modelo permite reconhecer os diversos fatores que influem diretamente na quantidade de radiação que é absorvida e refletida pelo planeta, influenciando diretamente nas variações das suas temperaturas superficiais. O pesquisador destaca que o ser humano interfere no clima terrestre, já que pode: "[...] variar a radiação infravermelha retida pela atmosfera terrestre pela variação de sua concentração de gases-estufa" (D13, p. 35). Entretanto, o próprio autor acrescenta que não é viável: “[...] fechar sentidos ou argumentar em favor de uma ou outra hipótese” (D13, p. 45).

Nesses trabalhos, são reveladas algumas das controvérsias que rodeiam o meio científico na tentativa de elencar causas para as mudanças climáticas, bem como algumas complexas relações entre os componentes do sistema climático. Desse modo, por meio da análise desses excertos, constata-se que está presente a ideia de que esse possa ser um fenômeno resultante da ação conjunta de diversos fenômenos, tanto naturais quanto antrópicos.

É importante destacar que, por sua complexidade inerente, não é possível elencar quais são as principais causas do fenômeno ou quais trazem mais impactos ambientais. Pelo mesmo motivo, também a interferência do ser humano sobre a natureza não pode ser descartada.

A complexidade deste fenômeno impede que sejam feitas afirmações categóricas sobre suas causas ou consequências. Ele constitui um sistema aberto, sujeito à interferência de diversas variáveis que podem ser elencadas como causas do fenômeno e que, ao mesmo tempo, podem agir conjuntamente na promoção de diversas consequências possíveis, mas não exatas. Como é questionado pelo pesquisador da dissertação D13 (p. 61): “Como se constrói acordos quando os problemas são complexos e podem ser abordados a partir de diferentes especialidades e recortes?”.

Os dados analisados também possibilitaram reconhecer as principais consequências das mudanças climáticas indicadas pelos autores das dissertações da área de EA: enquanto um grupo de dissertações (D2, D4, D5, D6, D8, D6, D9, D10 e D16) se concentra nas discussões sobre a consolidação das catástrofes climáticas, em outro grupo (D5, D6, D8, D10 e D16), o 
núcleo central dos argumentos se volta para os efeitos que as mudanças climáticas trarão para a economia, a sociedade e a saúde.

No primeiro grupo de trabalhos, aponta-se que o principal efeito das mudanças climáticas sobre o meio ambiente está relacionado com as elevações das temperaturas em diversos biomas terrestres. Indica-se, nessas pesquisas, que, em um futuro não muito distante, a elevação da temperatura média será responsável por causar “[...] aumento das áreas desérticas; expansão dos oceanos; diminuição das áreas litorâneas; tempestades violentas; perda de colheitas e aumento da vulnerabilidade de comunidades rurais" (D6, p. 100).

É fundamental que os cidadãos tomem contato com os estudos e as previsões sobre as mudanças no clima, sobretudo, porque há o risco real de que importantes catástrofes ambientais possam ocorrer por conta das alterações climáticas. Ao mesmo tempo, reconhece-se que a EA proporciona condições necessárias para inserir os cidadãos no âmago da questão, potencializando o senso da necessidade da transformação da relação que o ser humano estabeleceu historicamente com a natureza, a ponto de refletir e mudar essa relação.

Por outro lado, ao se tratarem as consequências das alterações climáticas nas práticas de EA, deve-se, também, ter em mente as considerações sobre as incertezas que acompanham o fenômeno. Não se pode deixar de lado que uma das características associadas aos fenômenos complexos é a impossibilidade da existência de um grau elevado de certezas sobre o futuro do sistema que ele compõe. Caos, flutuações e imprevisibilidade são características essenciais dos sistemas complexos, visto que as variáveis que estão envolvidas neste sistema podem encarregar-se de conduzi-lo a um estado que antes não fora previsto.

Já na dissertação D6, o autor apresenta os principais impactos que as mudanças climáticas trarão para a saúde humana, tendo em vista que as temperaturas mais elevadas estão associadas com: a proliferação de insetos causadores de doenças, como a dengue e a malária; inundações de áreas urbanas; a morte de inúmeras pessoas, como, por exemplo, no episódio das elevadas temperaturas verificadas na Europa em 2004, situação associada com a morte de trinta mil pessoas.

Na dissertação D8, há considerações sobre os efeitos que as mudanças climáticas trarão para a economia mundial. Segundo o autor, o aquecimento global tem origem antrópica, e esta situação leva diversos grupos sociais a propor a redução na emissão de dióxido de carbono, o que, por sua vez, gera inúmeros custos financeiros. Ainda segundo o pesquisador:

O IPCC acredita que para estabilizar o aumento da temperatura da Terra em dois graus Celsius - elevação considerada inevitável - os países precisarão reduzir suas emissões em $85 \%$ em relação aos níveis de 2000 até 2050. Para isso, haverá um gasto de $0,2 \%$ a 3\% do PIB global até 2030, em que esses recursos devem ser usados em tecnologias e medidas para então alcançar, em 2050, uma redução de até $85 \%$ em relação ao volume de 2000 das emissões de gases do efeito estufa, principalmente $\mathrm{CO}_{2}$. (D8, p. 4)

Geralmente, as medidas de mitigação envolvem muitas controvérsias e complexidades políticas, econômicas e sociais. Conforme apresentado no excerto anterior, as consequências que o fenômeno alcançará afetarão diretamente a economia da sociedade. Assim, compreende-se que a EA possui condições de promover uma reflexão minuciosa sobre as causas e os 
possíveis impactos das mudanças climáticas tanto sobre o ambiente quanto sobre o meio social, o que é capaz de provocar alguns questionamentos sobre a maneira com que o ser humano se relaciona a natureza.

Outro aspecto importante reside no fato de que a análise das dissertações também possibilitou avaliar a compreensão dos autores com relação aos processos de mitigação dos efeitos das mudanças climáticas. Esta análise indica que, em todos os textos, são apresentadas as principais medidas que os países devem adotar a fim de conterem o fenômeno, utilizando, embora de maneira inconstante, os conhecimentos ligados à economia e à política para discorrer sobre tais questões.

A complexidade dos fenômenos climáticos coloca todos diante de uma situação de risco, sobretudo, devido aos obstáculos que se apresentam nas tentativas de elaboração das previsões com alto grau de precisão. Nesta perspectiva, a autora da dissertação D1 entende ser fundamental a adoção de medidas preventivas, tendo em vista que a probabilidade de não se consumarem as catástrofes climáticas é a mesma de que esses fenômenos possam acontecer. Nas palavras da autora:

Por estarmos ainda iniciando nossa pesquisa nessa área, é importante tomarmos medidas para controlar as mudanças, como reduzir as emissões de gases estufa, mas não porque existe um aumento do Efeito Estufa natural, que ainda não é um fato cientificamente comprovado; essas medidas devem ser tomadas por conta da incerteza do conbecimento dos impactos que a atividade antropogênica pode causar. O planeta Terra existe há aproximadamente 4,6 bilhões de anos e estudamos o clima mais profundamente há menos de 200 anos. Não podemos ter uma conclusão definitiva nesse assunto, ainda tão pouco explorado, muito embora os modelos e dados sejam bastante consistentes dentro do estágio atual de nosso desenvolvimento científico. (D1, p. 53, grifos da autora)

Deve-se evidenciar o posicionamento de que, embora não se possa ter um elevado grau de certeza sobre a magnitude das alterações climáticas e dos seus efeitos, também não se pode afirmar que elas não se concretizarão, visto que o risco está sempre presente. Pensando no fato de que, se essas consequências climáticas desastrosas vierem a se concretizar, essas poderiam trazer grandes e irreversíveis problemas ambientais, sociais e econômicos. Por este motivo, muitos preferem seguir o princípio da precaução, “[...] segundo o qual atividades capazes de causar danos graves ou irreversíveis ao meio ambiente devem ser restringidas, antes que haja uma certeza científica absoluta de seus efeitos" (JURAS, 2008, p. 40).

Os autores das dissertações destacam como principais medidas de mitigação: redução na emissão de combustíveis fósseis; fontes de energia alternativa; sequestro de carbono; biocombustíveis e soluções tecnológicas. A medida de mitigação que é destacada em todas as dissertações analisadas remete à ideia de que: “[...] A primeira condição para se chegar a um clima estável é deter o aumento do teor de gases-estufa na atmosfera, de modo a não ocorrer qualquer intensificação do efeito estufa" (D16, p. 28).

De fato, a redução da emissão de $\mathrm{CO}_{2}$ é tida como uma das condições que podem minimizar alguns dos impactos ambientais causados pela intervenção do ser humano sobre a 
natureza, entretanto, entende-se que afirmar que esta seria uma das condições para se alcançar um "clima estável" é uma consideração passível de questionamento. Entende-se que a instabilidade é uma das características essenciais do clima, já que vários fenômenos interagem em uma rede complexa, sendo responsáveis por causar várias alterações climáticas.

Nos trabalhos analisados, também foi possível identificar apontamentos associados aos conflitos existentes entre as nações quando se discutem medidas de mitigação. A redução da emissão de dióxido de carbono por meio da queima de combustíveis fósseis possui várias implicações políticas e econômicas responsáveis por gerar alguns dissensos dentre os líderes políticos das nações mundiais que acompanham este debate. Martins e Ferreira (2010, p. 223) destacam que o tema mudanças climáticas encontra-se cercado pela incerteza e indeterminação que é responsável por estimular "calorosas controvérsias científicas”, o que desencadeia “[...] complicadas disputas internacionais onde estão colocados diferentes interesses e visões sobre o problema".

É importante destacar que muitas destas controvérsias estão diretamente relacionadas com os interesses da poderosa indústria do petróleo. Além disso, muitos países não estão dispostos a assumir elevados custos econômicos e sociais associados à modificação da indústria de base, tendo em vista que parte significativa dela é alimentada por combustíveis fósseis. Sobre esse aspecto, na dissertação D9, a pesquisadora discorre sobre a resistência de alguns governos em aderirem às medidas de mitigação propostas pelo protocolo de Kyoto:

A questão se tornou tão séria que passou a mobilizar debates internacionais, envolvendo lideranças mundiais. Em 1997, foi proposto o Protocolo de Kyoto (Japão), documento que impõe a redução gradativa das emissões de gases causadores do efeito estufa, especialmente do $\mathrm{CO}_{2}$, cuja principal fonte reside na queima dos combustíveis fósseis. [...] O protocolo, ratificado por mais de 140 países, não recebeu, no entanto, adesão dos EUA, que são grandes consumidores mundiais de combustíveis fósseis. (D9, p. 40-41)

O fator que interfere diretamente nestes processos de tomadas de decisão é, sem dúvida, o de cunho econômico. Conforme destacado pelo pesquisador da dissertação D11:

A maior dificuldade para a implementação do Protocolo é de ordem econômica. Os principais países poluidores como os Estados Unidos e o Japão continuam emitindo mais $\mathrm{CO}_{2}$ e teriam de alterar significativamente sua economia para atingirem as metas acordadas em Kyoto. Os Estados Unidos recusaram a ratificar o documento, alegando que suas economias seriam prejudicadas se o fizessem. (D11, p. 43)

Entende-se como significativo que as atividades de EA possam destacar considerações controversas como as acima destacadas, tendo em vista que elas revelam um mundo em que a complexidade das relações internacionais estabelecidas e os interesses políticos e econômicos estão por trás de muitos processos de tomada de decisão. De acordo com Veiga e Vale (2007), os diversos programas de retenção das mudanças climáticas, por envolverem questões políticas e econômicas, são uma das questões que mais estão rodeadas por aspectos complexos. 
Nesta perspectiva, constata-se que, nas dissertações, foram sugeridas diversas medidas a serem adotadas com a finalidade de reter o avanço do fenômeno das mudanças climáticas. Todavia, os autores também reconhecem que a adoção de medidas amplas e eficientes de mitigação esbarra na inexistência de consensos mínimos entre as nações mais influentes e poderosas do mundo. Não se pode deixar de lado que as intenções políticas, econômicas e sociais interferem na tomada de decisão relacionada com a intenção de aderir ou não às medidas de mitigação. Deste modo, aprovar e colocar em prática uma medida que tenha a intenção de "frear" os efeitos das mudanças climáticas não interferirá apenas no clima, mas, também, nos modelos de vida da sociedade como um todo.

Por outro lado, é importante destacar o fato de que, mesmo que essas medidas sejam adotadas, um sistema complexo nunca retornará a seu estágio inicial com as mesmas características apresentadas antes da intervenção. Mesmo que fossem reduzidas as emissões de gases poluentes, a atmosfera não voltaria a ser como era antes da deposição destes gases. De acordo com Watanabe-Caramello (2012, p. 223), “[...] as mudanças nos regimes dos sistemas naturais nunca retornarão ao ponto de partida. Em outras palavras, ao perceber que quaisquer que sejam as ações posteriores ao acontecimento, que pode ser um desmatamento ou despoluição, o sistema não retorna ao seu ponto original".

Na sequência deste trabalho, são apresentados dados que identificam como o fenômeno mudanças climáticas é apresentado e discutido nas atividades de ensino de EA presentes nas teses e dissertações analisadas nesta investigação.

\section{Articulações propostas entre práticas de Educação Ambiental e o tema mudanças climáticas}

Foram identificadas, no conjunto dos trabalhos que formam o corpus desta investigação, duas propostas educativas que envolviam diretamente o tema mudanças climáticas nas práticas de EA.

$\mathrm{Na}$ dissertação D13, o autor elaborou uma sequência de ensino de dez encontros, com duração de 100 minutos, que buscava apresentar o fenômeno Aquecimento Global como controverso. Essas aulas foram elaboradas para alunos do $1^{\circ}$ ano do Ensino Médio. Nessa sequência didática intitulada: "Aquecimento global e efeito estufa: a ciência por trás de uma controvérsia", o pesquisador buscou apresentar, aos participantes, as "[...] posições em desacordo de diferentes cientistas, além de questionar se seria possível afirmar a real ocorrência do fenômeno no momento presente, e se sim, quais seriam suas possíveis causas" (D13, p. 15).

Chama atenção o fato de que esta proposta educativa está voltada para a apresentação de controvérsias relacionadas com o tema mudanças climáticas. Para Silva e Carvalho (2007), a apresentação de temas controversos nas diversas atividades educativas é responsável por aguçar o senso crítico dos sujeitos envolvidos no processo educativo, visto que o contato com pontos de vista diferentes sobre o mesmo assunto contribui para a promoção de processos de tomada de decisões com base em conhecimentos científicos.

Outro ponto que merece destaque neste trabalho é a iniciativa de apresentar as incertezas relacionadas ao fenômeno, sobretudo, ao se propor um questionamento sobre se, de fato, o aquecimento global está ocorrendo. Considera-se que o trabalho educativo com incertezas e complexidades relacionadas ao fenômeno das mudanças climáticas pode contribuir para 
construir uma visão na qual este possa ser visto na perspectiva de um mundo pautado por processos evolutivos irreversíveis, em que o acaso e a necessidade estão entrelaçados. Neste caso, os valores da prudência e da solidariedade são fundamentais em um mundo aberto para processos de tomada de decisões, no qual a condição do risco está sempre presente.

A outra proposta de EA que envolve o tema mudanças climáticas apresenta um jogo didático sobre os temas resíduos sólidos, sustentabilidade e mudanças climáticas. Este jogo foi construído para alunos de um curso técnico (dissertação D16). A elaboração do jogo constituiu a primeira etapa da pesquisa, sendo a segunda representada pela sua aplicação a uma turma de um Curso Técnico em Agropecuária.

A análise desta proposta educativa indica que as questões diretamente ligadas às controvérsias associadas ao fenômeno das mudanças climáticas não se fazem presente neste trabalho. Com este material didático, a autora busca a conscientização dos estudantes em relação aos danos que a emissão dos gases do efeito estufa pode causar no sistema climático. Além disso, apresenta alternativas para reverter esta situação. Pode-se constatar que a relação entre causa e efeito é apresentada de maneira direta, e que os estudantes não são incitados a levarem em consideração os outros fatores que estão por trás do dilema existente entre poluir ou não poluir.

Além destas duas propostas educativas identificadas nestas dissertações, também foram constatadas, durante a leitura dos demais textos, algumas considerações dos autores sobre a abordagem das discussões relacionadas ao tema mudanças climáticas nas atividades educativas que abarcam a temática ambiental.

Um primeiro grupo de apontamentos refere-se às contribuições que o trabalho com o tema mudanças climáticas traria tanto para o reconhecimento da produção científica sobre o assunto quanto para a formação de cidadãos críticos, sobretudo, quando há a apresentação das controvérsias associadas ao tema. Um exemplo seria a dissertação D13, quando o autor considera a necessidade "[...] da escola pautar a discussão formal das controvérsias em torno ao fenômeno, fomentando nos estudantes a capacidade de avaliar argumentos e se posicionar enquanto participantes dos debates contemporâneos" (D13, p. 35).

Outras considerações fazem referência à interdisciplinaridade. No trabalho D9 (p. 22), a autora menciona que "O trato da problemática ambiental, diante da evolução e desenvolvimento conceitual do meio ambiente, passou a requerer um olhar multidisciplinar". Nesse sentido, a pesquisadora entende que "[...] fenômenos como o aquecimento global e a destruição da camada de ozônio, por exemplo, não podem ser trabalhados com base em uma única disciplina” (D9, p. 22-23).

Algumas reflexões ligadas com a contextualização, não para a Educação Básica, mas, sim, para o Ensino Superior, também foram identificadas na dissertação D11:

Neste sentido, a problematização das questões urgentes de nosso tempo histórico, como o aquecimento global e outras inúmeras questões devem fazer parte do projeto político pedagógico dos cursos de graduação, orientados para uma abordagem que identifique, problematize e proponha aos indivíduos uma nova racionalidade cultural, social, ambiental e educacional. (D11, p. 113-114) 
Por meio da análise das considerações dos autores das pesquisas, foi possível perceber, portanto, que são reconhecidas as contribuições que o trabalho com o tema mudanças climáticas - e fenômenos a ele relacionados - trariam para as práticas educativas.

\section{Considerações finais}

A partir deste trabalho, é reforçada a ideia de que a EA proporciona condições necessárias para apresentar, aos cidadãos, uma realidade ambiental complexa e controversa, potencializando o senso da necessidade de se transformar a relação que o ser humano estabelece com o meio ambiente, mas que, ao mesmo tempo, também incita o desenvolvimento de um senso crítico e questionador sobre estas questões. Desta maneira, reconhece-se a necessidade de se compreenderem os discursos que o campo da EA constrói a respeito da temática ambiental.

A análise das dissertações de EA que se referem ao fenômeno das mudanças climáticas apresenta dados que apontam para o fato de que os fenômenos ambientais são complexos. Enquanto outros dados indicam a existência de controvérsias associadas a este fenômeno. Porém, as complexidades e as controvérsias associadas às mudanças climáticas são pouco enfatizadas pelo campo de pesquisa da EA (aqui representado pelas dissertações selecionadas). Essas são, majoritariamente, enfocadas por meio do viés político e econômico, quando se trata sobre as medidas de mitigação. A consideração da existência de uma realidade climática sistêmica, não linear, probabilística e irreversível, e a complexidade dos modelos climáticos não são apresentadas de maneira direta, e podem ser identificadas em poucos excertos.

Quando enfatizadas, as controvérsias científicas são as mais apresentadas. Isto ocorre, sobretudo, ao se tratar das causas do fenômeno. As controvérsias políticas foram identificadas a partir da apresentação das dificuldades de um consenso político sobre a adoção das medidas de mitigação.

Neste trabalho, considera-se a necessidade de que as concepções sobre este tema sejam ampliadas pelo campo da EA, de modo que as complexidades e as controvérsias estejam mais presentes nos discursos elaborados neste campo de pesquisa.

Tendo em mente esse panorama acerca das compreensões apresentadas pelo campo teórico da EA sobre as mudanças climáticas, visto que a maior parte dos trabalhos analisados faz referência ao contexto escolar, entende-se que uma possível implicação desta pesquisa para estudos futuros seria a de investigar como as práticas escolares de EA têm apresentado a referida temática aos estudantes: há diferenças entre as concepções sobre o tema destacadas nessas práticas e aquelas identificadas nesta pesquisa? Quais os impactos que o destaque destas características do fenômeno traz para as práticas educativas?

Por fim, é importante apontar que a intenção desta investigação não está vinculada à elaboração de propostas educativas voltadas para o trabalho com o tema mudanças climáticas. Entendem-se as especificidades e os objetivos a serem alcançados em cada situação educativa. Não há, para a educação ou para a Educação Ambiental, uma prática que seja ideal ou uma "receita" a ser seguida. A prática educativa é influenciada por diversos fatores e obstáculos, ela desenvolve-se diante do aprendizado particular, mediante "erros e acertos" e com aportes teóricos específicos, que guiem as reflexões sobre o trabalho educativo. 
Análise de dissertações e teses brasileiras de Educação Ambiental: ...

\section{Agradecimentos}

A primeira autora deste trabalho agradece o apoio concedido pela Coordenadoria de Aperfeiçoamento de Pessoal de Nível Superior (CAPES).

\section{Referências}

ANDRADE, C. S. P. A complexidade da natureza e a natureza complexa dos problemas ambientais contemporâneos: pontos para reflexão. Revista de Geografia, Recife, v. 24, n. 1, p. 35-46, 2007. Disponível em: <http://www.ufpe.br/revistageografia/index.php/revista/ article/viewFile/94/64>. Acesso em: 28 nov. 2012.

BARDIN, L. Análise de conteúdo. 5. ed. Lisboa: Edições 70, 2009.

CAPES. Banco de teses. Disponível em: <http://bancodeteses.capes.gov.br>. Acesso em: 26 out. 2015.

CARVALHO, L. M. A temática ambiental e o processo educativo: dimensões e abordagens. In: CINQUETTI, H. S.; LOGAREZZI, A. (Org.). Consumo e resíduos: fundamentos para o trabalho educativo. São Carlos: EdUFSCAR, 2006. p. 19-41.

CARVAlHO, L. M. et al. A Educação Ambiental no Brasil: análise da produção acadêmica (dissertações e teses). Rio Claro: UNESP, 2009.

EARTE: estado da arte da pesquisa em Educação Ambiental no Brasil. Disponível em: <http:/ /www.earte.net/?page=criterios-selecao >. Acesso em: 22 out. 2015.

GUIMARÃES, M. Educação Ambiental: participação para além dos muros da escola. In: MELO, S. S.; TRAJBER, R. (Org.). Vamos cuidar do Brasil: conceitos e práticas em Educação Ambiental na escola. Brasília: MEC: MMA, 2007. p. 95-83.

JURAS, I. A. G. M. Aquecimento global e mudanças climáticas: uma introdução. Plenarium, Brasília, v. 5, n. 5, p. 34 - 46, 2008. Disponível em: <http://bd.camara.gov.br/bd/handle/ bdcamara/64>. Acesso em: 22 out. 2015.

LIMA, G. F. C. Mudanças climáticas e conservação social: riscos e alternativas ao aquecimento global. Gaia Scientia, João Pessoa, v. 3, n. 1, p. 35-46, 2009.

MARTINS, R.; FERREIRA, L. C. Oportunidades e barreiras para políticas locais e subnacionais de enfrentamento das mudanças climáticas em áreas urbanas: evidências de diferentes contextos. Ambiente e Sociedade, Campinas, v. 8, n. 2, p. 223-242, 2010.

MORIN, E. Introdução ao pensamento complexo. 3. ed. Porto Alegre: Sulina, 2007.

NICOLAI-HERNANDEZ, V. A.; CARVALHO, L. M. Controvérsias e conflitos socioambientais: possibilidades e limites para o trabalho docente. Interacções, Lisboa, v. 2, n. 4, p. 126-152, 2006. Disponível em: <http://revistas.rcaap.pt/interaccoes/article/ view/323/279>. Acesso em: 5 fev. 2013.

PRIGOGINE, I. O fim das certezas: tempo, caos e as leis da natureza. São Paulo: Ed. da Unesp, 1996. 
Reis, D. A.; Silva, L. F.

REIS, P. R. Ciência e controvérsia. Revista de Estudos Universitários, Sorocaba, v. 35, n. 2, p. 9-15, 2009. Disponível em: <http://repositorio.ul.pt/bitstream/10451/4615/1/ Ciencia-e-controversia.pdf $>$. Acesso em: 26 out. 2015.

RIBEIRO, R. A.; KAWAMURA, M. R.D. Educação Ambiental e temas controversos.

Revista Brasileira de Pesquisa em Educação em Ciências, Belo Horizonte, v. 14, n. 2, p. 159-169, 2014.

RUDDUCK, J. A strategy for handling controversial issues in the secondary school. In: WELLINGTON, J. (Ed.). Controversial issues in the curriculum. Oxford: Basil Blackwell, 1986. p. 6-18.

SILVA, L. F.; CARVALHO, L. M. A temática ambiental e o processo educativo: o ensino de física a partir de temas controversos. Ciência \& Ensino, Campinas, v. 1, p. 1-12, 2007. Número especial.

VEIGA, J. E.; VALE, P. M. Aquecimento global: um balanço das controvérsias. In: CICLO DE SEMINÁRIOS BRASIL NO SÉCULO XXI: DESAFIOS DO FUTURO. Atas... São Paulo: FEA/USP, 2007. p. 1-52.

WATANABE-CARAMELLO, G. Aspectos da complexidade: contribuições da física para a compreensão do tema ambiental. 2012. 246 f. Tese (Doutorado em Ensino de Ciências) Universidade de São Paulo, São Paulo, 2012.

Artigo recebido em 03/06/2014. Aceito em 24/08/2015. 